\title{
O CATALOGO GERAL DAS OBRAS DA BIBLIOTHECA DO GYMNASIO DE CAMPINAS E O REGISTRO CRHONOLOGICO DE ENTRADA: LIVROS E MANUSCRITOS EM DIÁLOGO NO ARQUIVO ESCOLAR (1896 A 1932)
}

\author{
Joel Martins Luz ${ }^{1}$ \\ Universidade Federal do Mato Grosso \\ abjm8@hotmail.com
}

\section{INTRODUÇÃO}

A história do livro e os seus espaços de ocupação têm sido informados, não poucas vezes, a partir dos grandes feitos históricos da humanidade. Não resta dúvidas, por exemplo, que a prensa móvel de Gutemberg caracterizou-se como um grande marco na produção massiva de livros e outros materiais impressos, com consequências não só na difusão do conhecimento, como também nas práticas de leitura, na escrita dos textos e na forma como a produção editorial vem sendo organizada e sistematizada para quem delas faz uso nos espaços ocupados (BURKE, 2002).

A história dos suportes, e das instituições que os preservam, tem sido edificada com os permeáveis resíduos de uma materialidade que sobreviveu ao tempo. São os relatórios enviados às inspetorias públicas, as correspondências com pedidos de compras e acuso de doações, os livros de tombo, os programas de ensino, os registros de empréstimos, devoluções e cartas de cobranças, os próprios livros e manuais remanescentes com suas marcas e inscrições de uso, catálogos e regimentos.

Este artigo propõe-se a apresentar um documento histórico, da centenária biblioteca do antigo Ginásio de Campinas, como fonte de estudo da circulação de livros e manuais escolares que compõem e compuseram seu acervo. Tal catálogo integra hoje, junto a uma diversidade de outros documentos o acervo do arquivo histórico da Escola Estadual "Culto à Ciência", de Campinas, e vem sendo preservado em parceria de longa data, entre a Escola e o Grupo de Estudos e Pesquisa em História da Educação, Cultura Escolar e Cidadania - CIVILIS, da Faculdade de Educação da Universidade Estadual de Campinas.

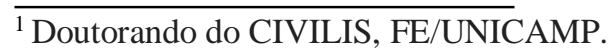




\section{ESSES DESCONHECIDOS, OS “LIVRO CATÁLOGOS” DE BIBLIOTECAS}

A história dos catálogos de bibliotecas como o próprio fim se justifica, nasceu da necessidade de ordenar o acúmulo dos manuscritos que passaram a ser reunidos em grandes depósitos a fim de serem preservados, sentenciando ao acervo uma ordem que refletisse o domínio do conhecimento recolhido e armazenado, de modo que o uso desse repertório pudesse facilmente ser localizado. Essa prática de controle não é recente e surge desde as bibliotecas antigas, tendo seu formato nos mesmos moldes dos suportes que os descreviam, em rolos de pergaminho que eram copilados em extensa lista, em formatos de livros, tendo se modernizado em fichas e mais recentemente, eletronicamente. Chartier (1998, p. 118), ao nos lembrar da grande Biblioteca de Alexandria com seus mais de 500 mil rolos de papiro, indica que o catálogo dessa biblioteca era constituído de cento e vinte rolos, o que nos põe a pensar o quão trabalhoso era a busca nesse catálogo, que despendia espaço para sua guarda e tempo para operá-lo manualmente.

Com o advento dos livros impressos e o incremento do comércio livreiro, da democratização da leitura e difusão das bibliotecas particulares, públicas e universitárias, os catálogos foram se tornando essenciais para a busca e recuperação das publicações. Foram se modernizando de tal forma, que suas descrições precisavam ser alfabetadas, divididas por assuntos, autores e notacionadas com códigos de localização. Afinal, "Preservar o patrimônio escrito frente à perda ou à corrupção suscita também uma outra inquietude: a do excesso. A proliferação textual pode se tornar obstáculo ao conhecimento. Para dominá-la, são necessários instrumentos de triar, classificar, hierarquizar (CHARTIER, 1998, p. 99).

Para Burke (2020, p. 176)

A existência de livros impressos facilitou mais do que nunca a tarefa de encontrar informações - desde que antes se encontrasse o livro certo. Para isso, foi preciso compilar catálogos para grandes bibliotecas, particulares ou públicas. Baillet compilou um catálogo em 32 volumes para seu patrão, o magistrado Lamoignon, um trabalho que ajuda a explicar seu desabafo, como já mencionado, sobre o advento de uma época de barbárie. A compilação desses catálogos criou o problema de como organizá-los. Por assunto ou por autor numa lista em ordem alfabética? Se por assunto, segundo o tradicional currículo das universidades ou de um modo novo e mais adequado às novas descobertas (um problema que, entre outros, preocupava Leibniz)? (BURKE, 2002, p. 176). 
Ainda segundo Chartier (1998, p. 34), as "primeiras ocorrências sistemáticas e ordenadas alfabeticamente de nomes de autores encontram-se nos índices dos livros e autores proibidos, estabelecidos no século XVI pelas diferentes faculdades de teologia e papados”. Essa prática consistia até então, na escritura de grandes calhamaços, pautados em folhas espessas, grossas, em que os bibliotecários criavam suas empíricas divisões e subdivisões, de acordo com os temas predominantes da coleção que dispunha a organizar.

No Brasil, essas práticas não foram diferentes. Rubens Borba de Moraes ao tratar das bibliotecas jesuítas, amparado nos relatos do Padre Antônio Vieira, narra que algumas delas, como: do Pará, Maranhão e Rio de Janeiro, possuíam grandes quantidades de livros e formavam as inúmeras bibliotecas de colégios e conventos, citando inclusive, a presença de "bons" bibliotecários como o próprio Padre Vieira, mas, um notável, Antônio da Costa "catalogou todos os livros por autor e matéria. É esse o primeiro catálogo verdadeiro de biblioteca brasileira e seu organizador, nascido, por sinal, em Lião, na França, o primeiro bibliotecário - e não um simples guardião de livros - que houve entre nós" (MORAES, 1979, p. 4).

Como documento fonte e suas possibilidades de leitura no contexto da história da educação, embora apresentando uma lacuna de estudos do tipo, Castro e Velazquez Castellanos (2015, p. 4556) sugerem que:

Essa fonte possibilita ao investigador, dependendo do seu interesse, inúmeras possibilidades interpretativas, tais como: a produção, a circulação e o consumo do livro em um dado lugar, em períodos determinados ou por diversificada parcela de leitores; a análise por temáticas distintas, por autores vários, pela tipologia das edições; e a compreensão pelos processos de liberdade ou de censura às formas de expressão e de pensamento, contidos nesses suportes culturais, assim como o seu uso como material escolar.

Talvez inaugurando a discussão, dois artigos destes autores abordam a análise desses objetos como fonte histórica, o primeiro tratou da análise de um catálogo manuscrito dando conta dos livros que compuseram a Biblioteca Pública Provincial do Maranhão no ano de 1829, que tinha a finalidade de atender à sociedade instruída e aos alunos do Liceu Maranhense (CASTRO; VELAZQUEZ CASTELLANOS, 2013). O segundo analisa, em perspectiva educacional, o catálogo do Gabinete Português de Leitura também do Maranhão, publicado em 1867. Destacou a trajetória do livro no Maranhão no período oitocentista, a história do Gabinete, e a análise do catálogo da Biblioteca, com a classificação e a ordenação dos livros, bem como as principais classes consultadas. (CASTRO; VELAZQUEZ CASTELLANOS, 2015).

Rev. Iberoam. Patrim. Histórico-Educativo, Campinas (SP), v. 6, p. 1-16, e020032, 2020. 
Embora esses trabalhos focassem no catálogo, como fonte histórica para o estudo da história do livro, leitura e da biblioteca no contexto da história da educação, as instituições que os produziram não se tratavam de fato de instituições de ensino, mas de difusão da leitura pública. Não menos importante, o Catálogo manuscrito da biblioteca do Ginásio de Campinas, constitui-se em fonte documental sobre a constituição da biblioteca histórica da instituição que hoje a abriga, bem como da circulação de livros e compêndios escolares, ainda pouco explorados.

\section{DAS NORMAS DOS “LIVROS CATÁLOGOS DE BIBLIOTECA”: ENTRE LEIS, DECRETOS, REGIMENTOS}

Desde a criação dos ginásios paulistas, uma parte dos investimentos da instrução pública, dentre outras, têm sido a instituição dos regimentos e outras instruções normativas para a organização do espaço e das práticas escolares. Estes regimentos eram organizados de modo que todas as escolas os seguissem, estes, comtemplavam desde a organização do ensino, os serviços administrativos e pedagógicos, nos quais a biblioteca estava inserida; não havia, portanto, uma normativa especifica para cada biblioteca que levasse em consideração a cultura interna de cada instituição. Acredita-se que um estudo das práticas bibliotecárias escolares, regidas por estes regulamentos, encontre algumas similaridades entre as instituições republicanas (grupos escolares, escolas reunidas, complementar, ginásios, etc.).

Embora, no Estado de São Paulo houvesse regimentos para todas elas, aqui abordamos apenas os regimentos dos ginásios uma vez que a produção cultural de suas bibliotecas reflete o propósito do catálogo aqui discutido. Em síntese, o quadro a seguir (QUADRO 1) nos mostra a partir da lei de instituição desses ginásios e outros decretos que reformaram a referida lei, a evolução das proposições das práticas de produção dos "livros catálogos” das bibliotecas escolares, a descrição e catalogação dos livros até 1930, no intuído de entender as condições em que foram produzidos, em especial, o da biblioteca do Ginásio Culto à Ciência de Campinas. 
QUADRO 1 - Legislação do ensino público paulista apontando normativas quanto às bibliotecas escolares 1892 a 1929. (preservou-se a ortografia original da fonte)

\begin{tabular}{|c|c|c|}
\hline ANO & LEGISLAÇÃO & SOBRE BIBLIOTECAS E CATÁLOGOS \\
\hline 1892 & $\begin{array}{l}\text { LEI N. 88, DE } 8 \text { DE } \\
\text { SETEMBRO DE1892 - Reforma } \\
\text { a instrucção publica do Estado }\end{array}$ & $\begin{array}{l}\text { Artigo 17. - Para o ensino secundario, } \\
\text { scientifico e litlerario, o Governo creará tres } \\
\text { gymnasios para alumnos externos. } \\
\text { Artigo 20 - Estes gymnasios serão providos de } \\
\text { laboratorios, gabinetes, collecções de historia } \\
\text { natural, bibliotheca e de todo o material } \\
\text { necessario para o ensino e os trabalhos praticos } \\
\text { dos alumnos. }\end{array}$ \\
\hline 1895 & $\begin{array}{l}\text { DECRETO N. } 293 \text { DE } 22 \text { DE } \\
\text { MAIO DE } 1895 \text { - } \\
\text { Approva o Regulamento dos } \\
\text { Gymnasios do Estado }\end{array}$ & $\begin{array}{l}\text { Artigo 147. - Cada Gymnasio terá uma } \\
\text { bibliotheca devidamente organizada, que } \\
\text { ficará sob a responsabilidade e guarda do } \\
\text { secretario. } \\
\text { Artigo 148. - Ao secretario como } \\
\text { bibliothecario compete: } \\
\$ \text { 1. }^{\circ} \text { - Organizar os necessario catalogos. }\end{array}$ \\
\hline 1897 & $\begin{array}{l}\text { DECRETO N. 503, DE } 18 \text { DE } \\
\text { DEZEMBRO DE 1897 - } \\
\text { Approva o Regulamento dos } \\
\text { Gymnasios do Estado }\end{array}$ & $\begin{array}{l}\text { Artigo 146. - Cada gymnasio terá uma } \\
\text { bibliotheca devidamente organizada, que ficará } \\
\text { sob responsabilidade e guarda do secretario. } \\
\text { Artigo 147. - Ao secretario como bibliothecario } \\
\text { compete; } \\
\text { § 1.0 - Organizar os necessarios catalogos. }\end{array}$ \\
\hline
\end{tabular}




\begin{tabular}{|c|c|c|}
\hline 1900 & $\begin{array}{l}\text { DECRETO N. 858, DE } 14 \text { DE } \\
\text { DEZEMBRO DE } 1900 \text { - } \\
\text { Approva o regulamento dos } \\
\text { Gymnasios do Estado }\end{array}$ & $\begin{array}{l}\text { Do secretario e bibliothecario } \\
\text { Artigo } 166 \text { - Em cada gymnasio do Estado, } \\
\text { haverá um secretario nomeado pelo Governo; } \\
\text { § unico - Esse funccionario accumulará o } \\
\text { exercicio do cargo de bibliothecario. } \\
\text { Artigo 170 - A secretaria de cada gymnasio terá } \\
\text { os seguintes livros além de outros que forem } \\
\text { sendo julgados indispensaveis pelo director: } \\
{[\ldots]} \\
1 \text { de entrada de obras para a bibliotheca; } \\
1 \text { de carga de carga de ressalvas de obras que } \\
\text { tenham de ser retiradas da bibliotheca pelos } \\
\text { lentes; } \\
\text { [...] } \\
1 \text { catalogo geral dos livros e papeis da } \\
\text { bibliotheca; } \\
\text { Artigo 171 - Cada Gymnasio terá uma } \\
\text { bibliotheca devidamente organizada, que ficará } \\
\text { sob a responsabilidade e guarda do secretario. } \\
\text { Artigo 172 - Ao secretario, como bibliothecario, } \\
\text { compete: } \\
\S 1 .^{\circ} \text { - Organizar os necessarios catalogos. } \\
\S 3 .^{\circ} \text { - Fazer a escripturação da bibliotheca, que } \\
\text { para isto terá os livros indispensáveis. } \\
\S 4 .^{\circ} \text { - Guiar os alumnos na consulta das obras.. }\end{array}$ \\
\hline 191 & $\begin{array}{l}\text { DECRETO N. 3.033,DE } 26 \text { DE } \\
\text { FEVEREIRO DE 1919 - } \\
\text { Manda cumprir o Regimento } \\
\text { Interno para os Gymnasios do } \\
\text { Estado }\end{array}$ & $\begin{array}{l}\text { Artigo 165. - Ao secretario, como } \\
\text { bibliothecario, compete: } \\
\text { \$ 1. - Organisar os necessarios catalogos; } \\
\text { Artigo } 171 \text { - Haverá ua Bibliotheca um livro de } \\
\text { registro de entradas onde serão lançadas, por } \\
\text { ordem chronologica, os nomes das obras, } \\
\text { revistas e mais papeis que forem adquiridos; um } \\
\text { catalogo das obras, pelas especialidades de que } \\
\text { tratam e os catalogos auxiliares que forem } \\
\text { julgados necessarios. (Art. 150) }\end{array}$ \\
\hline 1921 & $\begin{array}{l}\text { DECRETO N. 3.356, DE 31 DE } \\
\text { MAIO DE 1921 - Regulamenta a } \\
\text { Lei n.1750, de } 8 \text { de Dezembro de } \\
\text { 1920, que refôrma a Instrucção } \\
\text { Publica. }\end{array}$ & $\begin{array}{l}\text { Artigo 364. - Ao escripturario compete: } \\
\text { 1. }{ }^{\circ} \text { ) Ter sob sua guarda a Bibliotheca, } \\
\text { organizando-lhe o catalogo; }\end{array}$ \\
\hline
\end{tabular}




\begin{tabular}{|c|c|c|}
\hline 1926 & $\begin{array}{l}\text { DECRETO N. 4.166, DE 31 DE } \\
\text { DEZEMBRO DE 1926 - [...] } \\
\text { mandar pôr em execução nos } \\
\text { Gymnasios do Estado, o } \\
\text { Regimento interno que a este } \\
\text { acompanha. }\end{array}$ & $\begin{array}{l}\text { Artigo } 49 \text { - A secretaria de cada gymnasio terá } \\
\text { os seguintes livros, alem de outros que forem } \\
\text { sendo julgrados indispensaveis pelo director: } \\
\text { [...] } \\
1 \text { catalogo geral dos livros e papeis da } \\
\text { bibliotheca; } \\
\text { Artigo } 281 \text { - Ao secretario, como bibliothecario, } \\
\text { compete: } \\
\$ \mathbf{1 .}^{\mathbf{0}} \text { - Organizar os necessarios catalogos. } \\
\text { Artigo } 287 \text { - Haverá na Bibliotheca um livro de } \\
\text { registo de entradas onde serão lançadas, por } \\
\text { ordem chronologica, os nomes das obras, } \\
\text { revistas e mais papeis que forem adquiridos; um } \\
\text { catalogo das obras, pelas especialidades de que } \\
\text { tratam e os catalogos auxiliares que forem } \\
\text { julgados necessarios. }\end{array}$ \\
\hline 1929 & $\begin{array}{l}\text { DECRETO N. 4.600, DE } 30 \text { DE } \\
\text { MAIO DE 1929 - Regulamenta as } \\
\text { leis ns. } 2.269 \text {, de } 31 \text { de Dezembro } \\
\text { de } 1927 \text {, e } 2.315 \text {, de } 31 \text { de } \\
\text { Dezembro de } 1928 \text {, que } \\
\text { reformaram a Instrucção Publica } \\
\text { do Estado. }\end{array}$ & $\begin{array}{l}\text { Artigo 214. - Haverá em cada grupo ou escolas } \\
\text { reunidas, uma bibliotheca composta de obras } \\
\text { literarias, scientificas e especialmente } \\
\text { pedagogicas, de boas revistas illustradas, } \\
\text { destinada á consulta dos professores. } \\
\text { \$ 3. - O director, como responsavel pela } \\
\text { bibliotheca, organizará um catalogo dos livros } \\
\text { existentes, methodicamente classificados e no } \\
\text { qual mencionará o numero de ordem de cada } \\
\text { obra, sua estante, titulo, autor, encadernação, } \\
\text { procedencia e data da acquisição. } \\
\text { Artigo 218. - A escripturação será feita nos } \\
\text { seguintes livros: } \\
\text { h) um para o catalogo da bibliotheca com indice } \\
\text { al-phabetico; } \\
\text { Artigo 394. - Para a escripturação escolar } \\
\text { haverá: } \\
\text { m) um livro de catalogo da bibliotheca; }\end{array}$ \\
\hline
\end{tabular}

Fonte: Repositório da Assembleia Legislativa de São Paulo. Disponível em: https://www.al.sp.gov.br/alesp/pesquisa-legislacao/

Embora essas legislações se atenham muito mais ao funcionamento do ensino nos ginásios e menos nas suas repartições de apoio pedagógico (laboratorios, gabinetes, collecções de historia natural, bibliotheca), os excertos do quadro podem nos mostrar indícios de muitas praticas exercidas na produção dos registros bibliográficos e da movimentação desse material entre os lentes, professores e alunos da escola, sendo em "função deste lugar que se instauram os métodos, que se delineia uma topografia de interesses, que os documentos e as questões, que lhes serão propostas, se organizam" (CERTEAU, 2002, p. 66).

Os regimentos mostram que a proposta de instalação de bibliotecas junto aos ginásios

Rev. Iberoam. Patrim. Histórico-Educativo, Campinas (SP), v. 6, p. 1-16, e020032, 2020. 
ocorreu desde 1892 com a primeira reforma da instrução pública. Os outros documentos normativos, que vieram após esse ano, foram buscando incrementar as práticas dos serviços de organização dessas bibliotecas. A figura do Bibliotecário surgiu em 1893 pelo decreto Decreto $\mathrm{n}$. 218, de 27 de novembro de 1893, mas não como autônomo em que ele sozinho pudesse se dedicar aos afazeres da biblioteca que demandaria todo um trabalho minucioso de controle e registro dos livros; a princípio, essa carreira era exercida em função acumulada pelo secretário da escola, que a aliava com os trabalhos de escrituração da secretaria escolar, como o registro de matrícula, as correspondências, o controle dos livros de ponto, dentre outros.

Embora houvesse a presença do bibliotecário nesses primeiros anos de funcionamento da biblioteca, somente no ano de 1900 é que os regimentos incubem a este profissional a tarefa de organização dos catálogos, a elaborar a escrituração dos mesmos e guiar os alunos na consulta das obras. Além do "catálogo geral dos livros e papeis da Biblioteca" requeria que também houvesse um "livro de entrada de obras", e um de "ressalvas" indicando os livros que podiam ser retirados da biblioteca pelos lentes a título de empréstimo.

Em 1919 a prescrição quanto à organização dos catálogos era para que estes fossem classificados pela especialidade das áreas temáticas cobertas pela coleção de livros da biblioteca, e ainda, que a biblioteca pudesse elaborar outros catálogos que lhes fossem necessários. Em 1929 a recomendação era da modernização da técnica, para que se elaborasse um catálogo com um "índice alfabético".

\section{O FAZER DO "LIVRO CATÁLOGO": O “CATALOGO GERAL DAS OBRAS DA BIBLIOTHECA DO GYMNASIO DE CAMPINAS...”}

O "Catálogo geral de livros e papéis da Bibliotheca" (título na encadernação) (FIGURA 1), ou o "Catalogo geral das obras da Bibliotheca do Gymnasio de Campinas com o registro chronologico das entradas dos mesmas"3 (título do termo de abertura) (FIGURA 2), possui as dimensões de 46 × 33 x 5 cm dividido internamente em duas partes ${ }^{4}$. 
FIGURA 1 - Primeiro catálogo da Biblioteca do Ginásio de Campinas (1896-1932) (Na encadernação, lê-se: "Catálogo geral de livros e papeis da Bibliotheca").

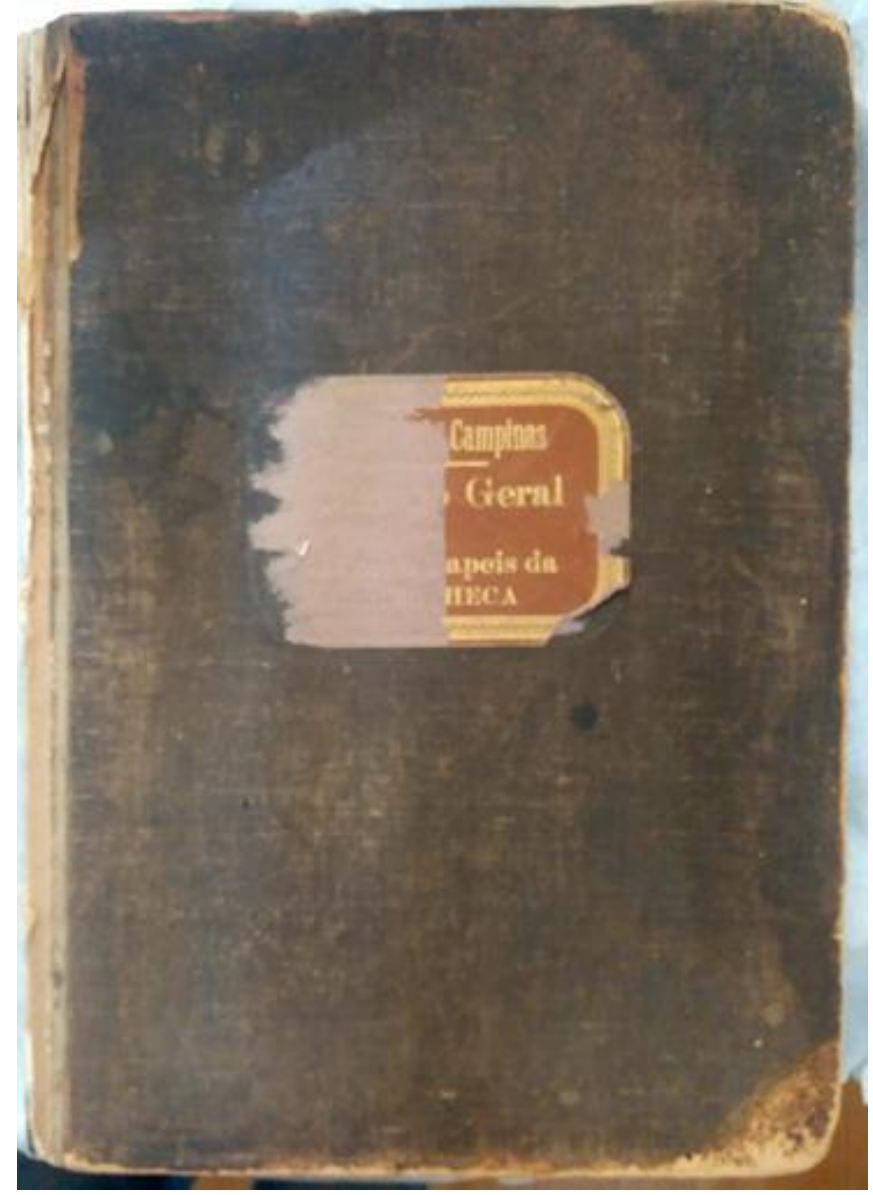

Fonte: Arquivo documental da Escola Estadual Culto à Ciência.

\footnotetext{
${ }^{3}$ Para este trabalho optou-se em utilizar o título que consta no termo de abertura do libro, por conter informações mais precisas do seu conteúdo, embora o nome/título da encadernação, para termos aquivísticos, também tem sua importância na recuperação da informação. Para discussões sobre essas questões, ver Camargo, et.all. (2015).

${ }^{4}$ As descrições aqui utilizadas foram retiradas em partes, da ficha de descrição tipológica documental elaborada pelo Grupo de pesquisa CIVILIS da Faculdade de Educação da Universidade Estadual de Campinas, que vem trabalhando na organização e inventariação do acervo há mais de 10 anos, sob a coordenação da Prof.a Maria Cristina Menezes.
} 
FIGURA 2 - Termo de abertura do livro catálogo.

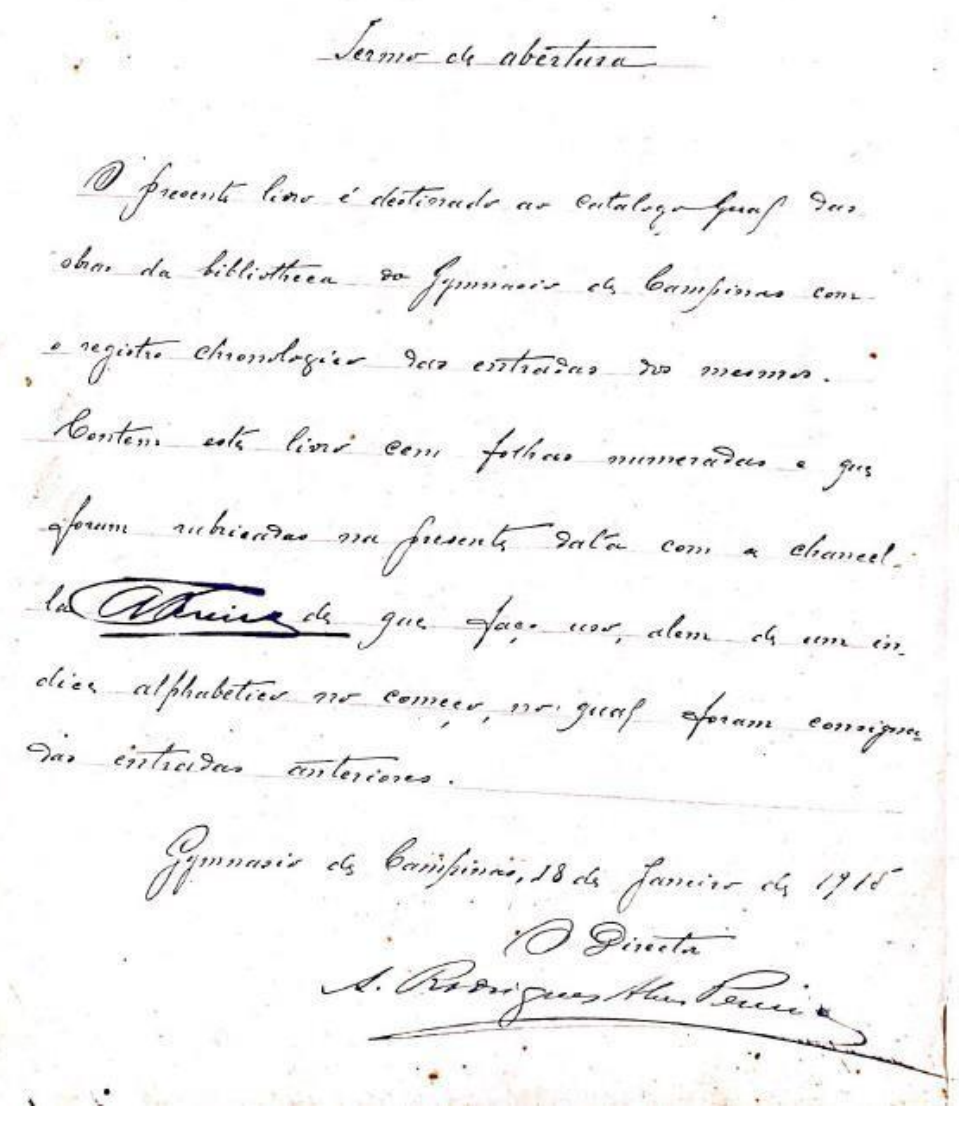

Fonte: Arquivo documental da Escola Culto à Ciência.

$\mathrm{Na}$ primeira parte, os livros estão arrolados por ordem alfabética, orinetados por um "classificador A/Z" de cor azul na lateral direita. Dentro dessa ordem, os registros são sequenciandos por ordem cronológica de entrada, como informa o título do termo de abertura, e os campos para a descrição localizados na margem esquerda (Dia, "mez" e "Anno"). Do meio da folha para a margem direita, utilizou-se o espaço em branco para a descrição dos títulos dos exemplares (FIGURA 3). À bico de pena, as grafias e caligrafias foram se alternando na medida em que os anos se passaram, um retrato das várias mãos que compuseram os registros. Esse primeiro formato teve seu último registro no ano de 1912, iniciando sua ou parte a partir de 1915. 
FIGURA 3 - Aspecto interno do livro com subdivisão alfabética e com a descrição dos livros apenas pela data de entrada.

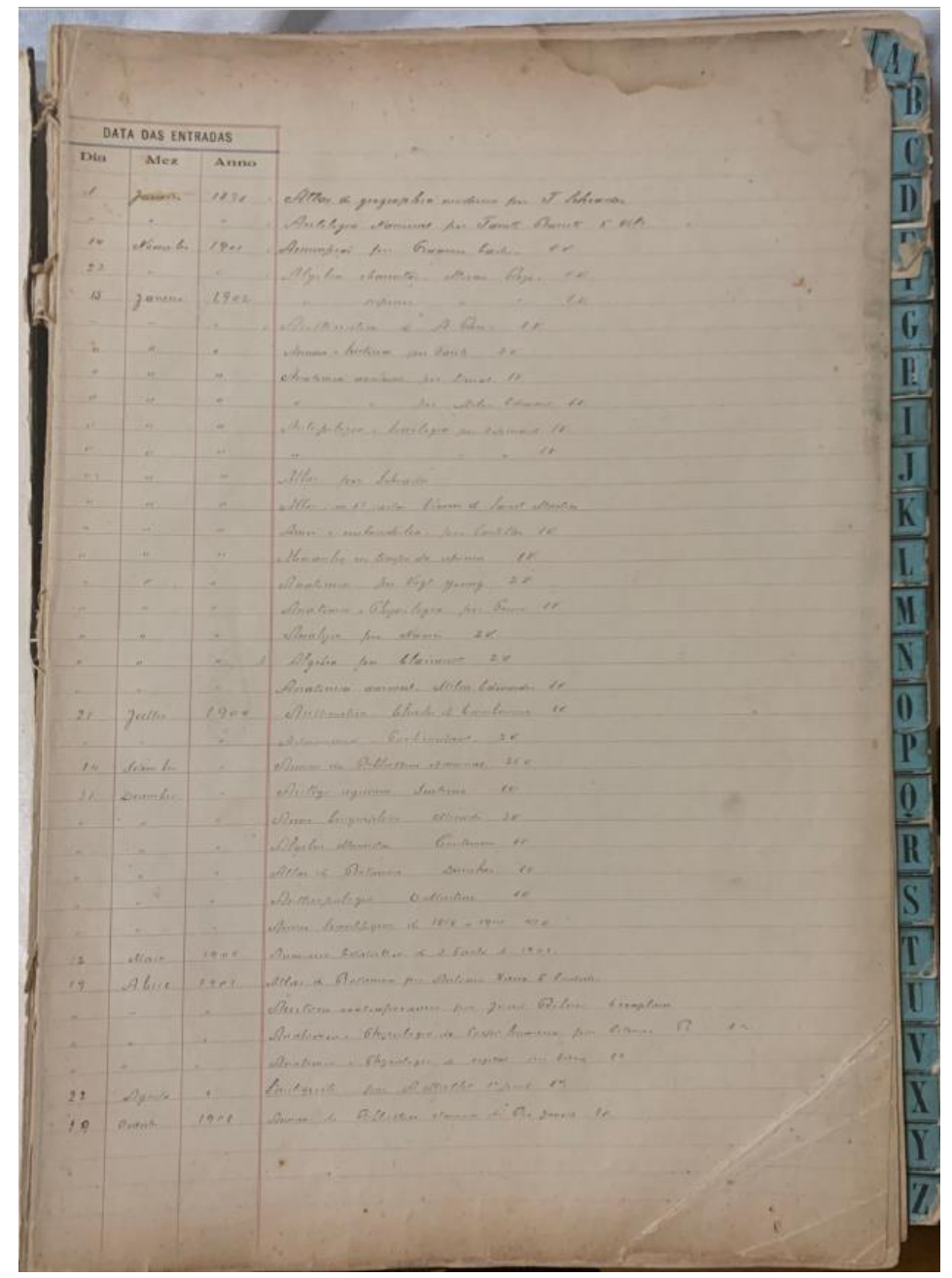

Fonte: Arquivo documental da Escola Culto à Ciência.

A segunda parte do catálogo está paginada de 1 a 100, a partir do ano de 1915 aos campos já impressos no livro, são acrescentados manualmente à régua com tinteiro vermelho pelo escriturário, o "Nome dos autores" em que era descrito o autor do livro; a "denominação das obras" constando o título do livro; o " $\mathrm{n}^{\mathrm{o}}$ de vol.", em se tratando de livros em mais de um volume ou fascículos, em caso de periódicos que também eram ali catalogados; a "língua", indicando o idioma do livro; a "procedência", tratando do editora, livraria ou casa publicadora; e o " $n^{\circ}$ catálogo", em que parece contar um tipo de sistema de localização do livro na estante5 (FIGURA 4). Aqui, todas as páginas são rubricadas por uma assinatura carimbo. 
FIGURA 4 - Acréscimos de campos para descrição dos livros ocorridos após 1915.

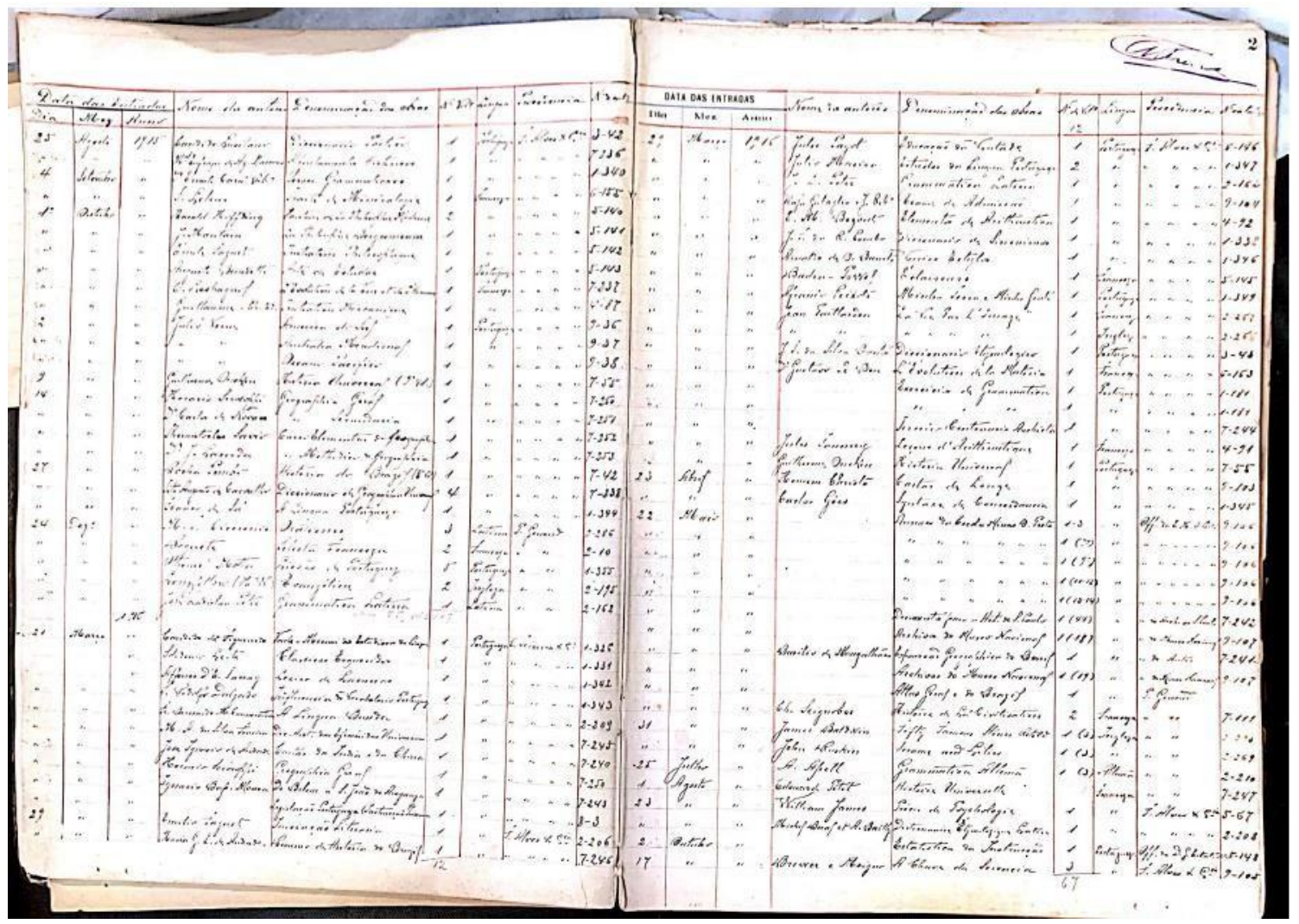

Fonte: Arquivo documental da Escola Culto à Ciência.

Como se pode ver no QUADRO 1, antes mesmo da criação do ginásio em 1895, com a reforma da instrução pública paulista, o regimento passa a exigir a necessidade de catálogos na organização dos acervos escolares. Porém, a respeito desse catálogo, pesa uma grande dúvida sobre a sua elaboração em relação ao início da instalação da biblioteca em 1896 junto com a escola, como informa sua data-limite. As informações da capa e as descrições internas dos livros, consta que seu registro teve início a partir de 1896, no entanto, em uma leitura mais atenta, no termo de abertura do livro consta como aberto em 1915. Coincidentemente, até 1915 os registros eram feitos em forma de listagem apena arrolando a data de entrada e com os títulos sequenciados alfabeticamente. Só a partir deste ano é que os dados aparecem mais completos em termos catalográficos. Ao que parece, supõe-se que pelo menos neste livro essa catalogação tenha sido elaborada de forma retrospectiva no ano de 2015, pondo em dúvida o início da biblioteca.

\footnotetext{
${ }^{5}$ Nos livros, esse mesmo código encontra-se no carimbo da instituição no campo "No". Indica, ao que parece, o número da estante/prateleira separado por um hífen a um número de ordem
} 
De acordo com os registros bibliográficos do catálogo, o acervo tinha preferencialmente uma vocação didática. Não havia muitos exemplares, mas o básico para atender aos programas de ensino, por isso nesse primeiro momento a biblioteca era composta basicamente pelos manuais e compêndios. Havia poucos títulos para uma leitura mais recreativa, exceto para os grandes clássicos que compunham também as aulas de literatura, latim, italiano e francês, como "Cachoeira de Paulo Afonso" (1901), de Castro Alves; "Fabulas de La Fontaine” (1896), traduzido pelo Barão de Paranapiacaba; “O Guarani”" (1901), de José de Alencar; "Ilíada” (1901), de Homero com tradução de Odorico Mendes; “Os Lusíadas" (1902), de Camões; “Selecta clássica” de João Ribeiro.

No decorrer dos anos, o catálogo foi se estendendo em número de registros, refletindo significativamente a quantidade do número de livros que foram sendo adquiridos por compra e doações, tanto dos próprios lentes dos ginásios, quanto de importantes instituições científicas como como a Biblioteca Nacional do Rio de Janeiro, que enviava regularmente seus "Annaes da Bibliotheca Nacional" (1902), constando no catálogo 25 exemplares no acervo.

Nos rastros das leituras, encontra-se em meio a relação dos livros, um termo de uma reunião realizada em 1905 na "sala da Bibliotheca", reunindo o diretor interino do Ginásio, o Sr. Dr. Eduardo Gê Badaró, o lente João Von Atzingen e o amanuense Benedicto Oliveira, com o intuito de proceder o "anulamento" de quatro exemplares do livro "Lições elementares da língua inglesa", dos seis constantes no referido catálogo, por não mais constar no acervo.

Uma contagem simples no referido catálogo contabilizou o registro de 2.403 títulos de livros no período da sua data-limite, sem considerar o número de volumes/itens de cada título, tendo alguns deles, a existência de até 7 itens, é possível que o acervo tenha registrado até o ano de 1932 cerca de 4/5000 unidades.

\section{CONSIDERAÇÕES FINAIS}

Em especial no Estado de São Paulo, a produção desses catálogos em formatos de livros de registro, parece que esteve mais relacionada às práticas de escrituração da escola do que servir propriamente com o fim de um catálogo de biblioteca, isto porque, como dito, a legislação prescrevia ao secretário escolar a tarefa de zelar pela biblioteca dos ginásios, tornando ele também um bibliotecário, mas não se sabe se as funções da biblioteca eram desprestigiadas em detrimento

Rev. Iberoam. Patrim. Histórico-Educativo, Campinas (SP), v. 6, p. 1-16, e020032, 2020. 
das funções da secretaria. Na biblioteca do Ginásio de Campinas, todo o controle dos livros que entravam na biblioteca era nele registrado, primeiramente em ordem cronológica e depois em ordem alfabética dos títulos das obras.

Nas palavras de Deaecto (2017, p. 157), ao analisar o catálogo da primeira biblioteca pública de São Paulo, podemos inferir também que, embora o bibliotecário tivesse a preocupação com a descrição dos dados dos livros, separando-os por áreas ou alfabeticamente, a sua elaboração tinha uma similaridade com um livro de tombo ou controle patrimonial. Isso se evidente ainda pelas marcas de inventariação escritas à lápis pelo bibliotecário, nos cantos inferiores do catálogo. Notase, ainda, que o catálogo não servia para o uso dos alunos do ginásio, até mesmo porque, como se vê na legislação da época, o empréstimo era facultado apenas aos lentes e a consulta aos livros pelos alunos ocorria no recinto da biblioteca, talvez por medida de segurança, devia ser acompanhado pelo bibliotecário, não se tinha o livre acesso às estantes, o que nos leva a acreditar que os alunos buscavam os livros por indicação dos seus lentes.

Mesmo com esse entendimento reduzido de suas funções, não se pode negar o intento de um verdadeiro catálogo de biblioteca. É visível, pelas informações da capa, esse propósito, bem como a evolução dos campos de descrição bibliográfica, a partir de 1915, aos quais também foi adicionado um código de localização dos livros nas estantes, que por sinal, reflete o crescimento do acervo e a necessidade de uma melhor ordenação. É possível pensar que mesmo em formato de listagem o catálogo tenha cumprido sua função, pois era ele com todas as suas limitações que dava conta dos títulos de obras existentes, permitia a contagem por meio dos inventários e relatórios que eram remetidos à Repartição de Estatística e Arquivo do Estado ${ }^{6}$.

Ao código de arranjo e ordenação dos livros utilizado na Biblioteca do Ginásio de Campinas, o catálogo nos dá pista do formato de sistematização que se dava nesta essa biblioteca, como da disposição das estantes e a sequência das prateleiras na ordem dos livros. Informação tão importante, que se pensarmos que esses livros foram arranjados por assunto (química, física, matemática, gramatica, etc.), por conseguinte, estes assuntos espelham, como diz Burke (2003, p. 88) ao analisar os sistemas de classificação das bibliotecas universitárias europeias, que a "ordem dos livros [...] reproduzisse a ordem do currículo das universidade"

\footnotetext{
${ }^{6}$ Consta correspondência expedida, devolvendo à Repartição de Estatística e Arquivo do Estado, questionário sobre o movimento da biblioteca (Cópia de ofícios. Oficio 31 de agosto de 1916), assinado pelo Secretário-Bibliotecário do Ginásio de Campinas
} 
Outra faceta do catálogo, está nas informações sobre o idioma de cada livro. Um campo que aparece na segunda parte do catálogo e que nos possibilita entender não só o domínio linguístico dos lentes e como se deu o ensino de línguas por meio dos compêndios adotados nos programas de ensino. Outrossim, possibilita a compreensão de toda a movimentação para a aquisição dos livros, o contato com casas importadoras, a influencia que esses livros tiveram na composição pelos lentes de outros manuais que anos depois passaram a ser adotados pelo ginásio e o processo de apropriação cultural desses livros, como bem diz Espagne (2012, p. 21) sobre o acúmulo desses impressos estrangeiros em bibliotecas.

A ordem cronologia de entrada de livros permite conhecer os primeiros manuais que deram início ao fundo bibliográfico. No entanto a ausência das datas de publicação dos livros impossibilita a identificação dos exemplares mais antigos. Um confronto profundo desse rol hoje, com os livros remanescente na biblioteca histórica e em catálogos como o da Biblioteca Nacional, será possível rastrear e recuperar essa profusão de elementos construtivos da cultura material dessa importante biblioteca de Campinas.

Por fim "Graças a difusão dos catálogos, o mundo fechado das bibliotecas singulares pode ser transformado em um mundo infinito de livros assinalados, recenseados, visitados, consultados e, eventualmente, emprestados" (CHARTIER, 1999, p.74).

\section{REFERÊNCIAS}

BURKE, Peter. Uma história social do conhecimento, v.1: de Gutenberg a Diderot. Rio de Janeiro: Zahar, 2003.

BURKE, Peter. Problemas causados por Gutenberg: a explosão da informação nos primórdios da Europa moderna. Estudos Avançados, v.16, n. 44, 173-185, 2020. Disponível em: http://www.revistas.usp.br/eav/article/view/9854. Acesso em: 01 dez. 2019.

CAMARGO, Ana Maria de Almeida, DELMAS, Bruno, ARDAILLON, Danielle, et al. (Orgs.). Dar nome aos documentos: da teoria à prática. São Paulo: Instituto Fernando Henrique Cardoso, 2015. Disponível em: https://fundacaofhc.org.br/files/dar_nome_aos\%20documentos.pdf. Acesso em: 01 dez. 2019.

CASTRO, Cesar Augusto; VELAZQUEZ CASTELLANOS, Samuel Luis. O catálogo como fonte para a história (do livro, da leitura e da educação) no Maranhão Império. Cadernos de História da Educação (Online), v. 12, p. 455, 2013. Disponível em: http://www.seer.ufu.br/index.php/che/article/view/25014/13908. Acesso em: 06 nov. 2020. 
CASTRO, Cesar Augusto; VELAZQUEZ CASTELLANOS, Samuel Luis. O lugar do livro e da leitura no Maranhão Oitocentista: o Gabinete Português de Leitura. Outros Tempos, v. 13, p. 243258, 2015. Disponível em:

https://periodicos.sbu.unicamp.br/ojs/index.php/rdbci/article/view/2118. Acesso em: 06 nov. 2020.

CERTEAU, Michel de. A escrita da história. 2. ed. Rio de Janeiro, RJ: Forense Universitária, 2002. 345 p.

CHARTIER, Roger. A aventura do livro: do leitor ao navegador, conversações com Jean Lebrun. São Paulo: Imprensa Oficial do Estado de São Paulo/Editora UNESP, 1998.

CHARTIER, Roger. A ordem dos livros: leitores, autores e bibliotecas na Europa entre os séculos XIV e XVIII. 2. ed. Brasília: UnB, 1999. 111p.

DEAECTO, Marisa Midori. A Cidade e os Livros ou Como Formar uma Biblioteca?: Notas Históricas Sobre a Primeira Biblioteca Pública de São Paulo (1825 - 1887). Perspectivas em Ciência da Informação (on line), v. 22, p. 152-167, 2017. Disponível em: https://www.scielo.br/pdf/pci/v22nspe/1413-9936-pci-22-spe-00152.pdf . Acesso em: 06 nov. 2020.

ESPAGNE, Michel. Transferências culturais e história do livro, LIVRO - Revista do Núcleo do Livro e da Edição, n. 2, p. 21-34, ago. 2012.

MORAES, Rubens Borba de. Livros e bibliotecas no Brasil colonial. Rio de Janeiro, RJ; São Paulo: Livros Técnicos e Científicos: Secretaria da Cultura de Ciências e Tecnologia, 1979. 234p.

VIDAL, Diana Gonçalves. O exercício disciplinado do olhar: livros, leituras e práticas de formação docente do Instituto de Educação do Distrito Federal (1932-1937). Bragança Paulista: USF, 2001. 343p.

Recebido em: 26 de dezembro de 2020. Aceito em: 30 de dezembro de 2020. 